\title{
$-O$ The Spatial Distribution of Economic Activities in Italy
}

Laura de Dominicis'

Giuseppe Arbia ${ }^{2}$

Henri L.F. de Groot ${ }^{1,3}$

\footnotetext{
' VU University Amsterdam;

2 "G. d'Annunzio" University, Pescara, Italy;

3 Tinbergen Institute.
} 


\section{Tinbergen Institute}

The Tinbergen Institute is the institute for economic research of the Erasmus Universiteit Rotterdam, Universiteit van Amsterdam, and Vrije Universiteit Amsterdam.

Tinbergen Institute Amsterdam

Roetersstraat 31

1018 WB Amsterdam

The Netherlands

Tel.: $\quad+31(0) 205513500$

Fax: $\quad+31(0) 205513555$

Tinbergen Institute Rotterdam

Burg. Oudlaan 50

3062 PA Rotterdam

The Netherlands

Tel.: $\quad+31(0) 104088900$

Fax: $\quad+31(0) 104089031$

Most TI discussion papers can be downloaded at http:/ /www.tinbergen.nl. 


\title{
The Spatial Distribution of Economic Activities in Italy
}

\author{
A sectorally detailed Spatial Data Analysis using Local Labour Market Areas
}

\author{
Laura de Dominicis \\ Vrije Universiteit, Amsterdam, The Netherlands \\ Giuseppe Arbia \\ Faculty of Economics, “G. d'Annunzio" University, Pescara, Italy \\ Henri L.F. de Groot ${ }^{\dagger}$ \\ Vrije Universiteit, Amsterdam and \\ Tinbergen Institute, Amsterdam-Rotterdam, The Netherlands
}

\begin{abstract}
Existing indices measuring the spatial distribution of economic activity such as the Krugman Specialisation Index, the Hirschmann-Herfindahl index and the Ellison-Glaeser index typically do not take into account the spatial structure of the data. In this paper, we first consider traditional measures of geographical concentration, and subsequently extend the analysis to take spatial dependence into account. Using data for Italy for the years 1991 and 2001, we apply exploratory spatial data analysis to identify sectoral location patterns in both the manufacturing industry as well as in services. We find that large differences prevail in the geographical concentration of production across sectors. The results of the exploratory spatial data analysis reveal the existence of welldefined clusters of economic activities.
\end{abstract}

JEL codes: $\quad \mathrm{C} 12, \mathrm{R} 12, \mathrm{R} 30$

Keywords: $\quad$ Exploratory Spatial Data Analysis, Geographic Concentration, Italy, Spatial Autocorrelation

\footnotetext{
Corresponding author: Department of Spatial Economics, Vrije Universiteit Amsterdam, De Boelelaan 1105, 1081 HV Amsterdam, The Netherlands, hgroot@feweb.vu.nl, fax: +31 205986004
} 


\section{Introduction}

Agglomeration economies play an important role in explaining regional development, regional growth and industrial location. New Economic Geography theories have substantially contributed to stimulate the revival of interest in the empirical description and in the explanation of industrial patterns of agglomeration (Krugman, 1991). This paper aims to take this literature a step further. We investigate spatial patterns in the distribution of economic activities paying explicit attention to spatial dependencies that may arise among territorial units and that have hitherto been largely neglected.

The literature on geographic concentration of industries and agglomeration at least goes back to Marshall (1890). A number of forces - also referred to as localization economies - make it advantageous for firms in the same industry to locate in close proximity. Geographical proximity eases communication, facilitates technological spillovers between firms in the same industry, induces efficient provision of intermediate inputs at a lower cost, and allows firms to share a larger market for inputs and outputs, in particular a local skilled labour pool. Next to localization economies, there are other types of forces, also known as urbanization economies, which drive firms of different industries to locate close to one another (Jacobs, 1969). This phenomenon has been often observed at the level of urban agglomerations. The sources of urbanization economies are rather diverse, but in general comparable to the ones that generate localization economies. ${ }^{1}$

A number of studies investigated the geographical dispersion in the manufacturing sector in the US (Ellison and Glaeser, 1997; Kim, 1995 and 1999; Hanson, 1998). Midelfart-Knarvik et al. (2004) have largely discussed the changes that occurred in Europe in recent decades. ${ }^{2}$ In Europe, we find also a number of studies considering spatial concentration at a sub-national level. Maurel and Sédillot (1999) offer an empirical investigation of the geographic concentration of French industries. Alonso-Villar et al. (2004) observe the existence of a major geographic concentration in a number of high-tech industries in Spain. This study also shows that the higher the technological level of the industry, the higher the agglomeration it experiences. Braunerhjelm and Johansson (2003) examine the spatial concentration of Swedish production in the manufacturing and service industries. Most concentration measures fail to consider the space in which a particular industry is located. Spatial dependence in the distribution of economic activities in Catalonia is taken into account in Ruiz-Valenzuela et al. (2007). Guillain and Le Gallo (2006) suggest a methodology allowing the measurement of the degree of spatial agglomeration and the identification of location

\footnotetext{
${ }^{1}$ Unlike localization economies, which emerge when the number of firms in the same industry in a certain area increases, urbanization economies are a function of city size.

${ }^{2}$ For a comprehensive survey of studies on geographic concentration in Europe see Combes and Overman (2004).
} 
patterns. They applied this approach to the Paris area and observed that traditional measures of geographical concentration and methodologies that account for spatial dependence need to be considered jointly, in that they provide different and complementary information about the concentration of the various sectors. ${ }^{3}$

In our application, we investigate the spatial distribution of economic activities in Italy in the manufacturing industry and services. Italy serves arguably as a particularly good case-study to measure the extent to which economic activities tend to cluster in space. First, Italy possesses a peculiar industrial structure characterised by a small number of densely populated industrial clusters, opposed to a wide set of areas where some employment can still be found. A second important advantage comes from the richness of our dataset, which allows us to measure geographic concentration across a very large number of regions, and for a large set of industry sectors. More specifically, we rely on a large dataset containing industry and employment data for 23 manufacturing industries and 17 service sectors, for the years 1991 and 2001.

Building on the work in Guillain and Le Gallo (2006) on the Paris area, this study takes their approach a step further along two dimensions. First, we perform the analysis on the entire national economy using unique detailed data at a geographical as well as a sectoral level. We thus go beyond the analysis of a specific region and simultaneously consider the manufacturing as well as the service sector. In addition, we improve the approach proposed by Guillain and Le Gallo (2006) by taking into account the size distribution of firms when looking at the geographical concentration of economic activities.

The paper is structured as follows. Section 2 presents and characterizes the data. Section 3 analyzes agglomeration of manufacturing and service industries in Italy. Section 4 extends the analysis to account for spatial dependence, where both global and local spatial dependence are considered. Section 5 concludes.

\section{Description of the data}

Our analysis rests on a large dataset containing data on the number of employees and the number of plants in Italy for the years 1991 and 2001. The industry is defined at the NACE 2-digit sector level, and the data refer to 24 manufacturing sectors (including construction) and 17 service sectors. ${ }^{4}$ The Italian National Statistical Office (ISTAT) runs census surveys on the industry and the service

\footnotetext{
${ }^{3}$ Some other authors employ a rather different approach, which is not based on the standard concentration measures, but aims at studying the spatial clustering of activities in a continuous space. Such an approach was introduced by Arbia and Espa (1996) and subsequently exploited by, amongst others, Marcon and Puech (2003) for France, Quah and Simpson (2003) and Duranton and Overman (2005) for the clustering of industries in the UK and by Arbia et al. (2007) for the co-agglomeration of high-tech industries in Italy.

${ }^{4}$ See the Appendix for a complete list of the sectors included in the dataset.
} 
sectors on regular decennial intervals. The dataset provides very detailed information both at a geographic (around 8,100 Italian municipalities) and industrial level (up to 3-digit NACE industries) related to the number of plants and the number of workers of all Italian firms. ${ }^{5}$ Our dataset presents a further advantage. Contrary to most of the previous studies investigating the geographical concentration of economic activities (Ellison and Glaeser, 1997; Maurel and Sédillot, 1999) there is no problem of withheld data in our sample.

For our analyses, we employ data measured at the level of functional regions. A functional region is a territorial unit that is defined and classified by looking at patterns of spatial interaction or spatial organization, and in which there is an overall coherence to the structure and dynamics of political, economic, and social organization. The use of administrative units would be problematic for two major reasons: first, administrative boundaries are static and usually resulted from historical, political, and social events; second, economic clusters and polarisations oftentimes exist at spatial scales that go beyond the traditional administrative boundaries. In Italy the concept of functional regions has been used to identify a large number of Local Labour Market Areas, known as Local Labour Systems. The Local Labour Systems (LLSs) are aggregations of two or more contiguous municipalities identified on the basis of the self-containment of the daily commuting flows between the place of residence and the place of work. In practice, an area can be considered a local labour system when there is evidence of a concentration of residential activities (such as most individual and family consumption), of work activities (such as expenses for production and distribution) as well as of those social relations that are created within it. ${ }^{6}$ The Italian National Statistical Office updates the number of the LLSs every ten years. For the sake of comparability, we consider in our analysis the territorial subdivision of Italy in LLSs according to the 2001 classification and we apply it also for data of $1991 .^{7}$

\section{Geographic concentration of economic activities in Italy}

To measure the extent to which an industry is geographically concentrated we follow the approach proposed by Ellison and Glaeser (1997). The advantages of this approach are twofold. First, it

\footnotetext{
${ }^{5}$ Starting from a dataset at the municipal level, we aggregate the data into larger administrative units (more specifically, NUTS3 and NUTS2 regions) and into functional regions (local labour market areas, or LLMAs). Results for the NUTS regions are available from the authors upon request.

${ }^{6}$ The European Commission has recently recognized the central role of the LLSs. Following a period of negotiation between the European Authorities and the Italian Government the LLSs have become the territorial units used by the EU to identify the areas eligible under the Objective 2 in the Northern and Central regions of Italy for the 2000-2006 programming period (Commission Decision 2000/530/EC of the 27 July 2000).

${ }^{7}$ The 955 local systems originally identified in 1981 were reduced to 784 in 1991 and further to 686 in 2001.
} 
builds on a rigorous statistical model in which a situation of random distribution of economic activities across the spatial units is taken as a benchmark. Second, the index is able to correct for the fact that in industries consisting of few relatively large plants, industry concentration may appear to be higher than it is in reality. For a country like Italy, where the industrial structure is characterized by a small number of large plants (for example, FIAT in Turin) and a large number of firms of small and medium size, a measure providing proper weight to these two extreme cases is relevant. Ellison and Glaeser (1997) propose the following statistic to measure geographical concentration, denoted by $\hat{\gamma}_{E G}:^{8}$

$$
\hat{\gamma}_{E G} \equiv \frac{G-\left(1-\sum_{i=1}^{N} x_{i}^{2}\right) H}{\left(1-\sum_{i=1}^{N} x_{i}^{2}\right)(1-H)} \equiv \frac{\sum_{i=1}^{N}\left(s_{i}-x_{i}\right)^{2}-\left(1-\sum_{i=1}^{N} x_{i}^{2}\right) \sum_{j=1}^{M} z_{j}^{2}}{\left(1-\sum_{i=1}^{N} x_{i}^{2}\right)\left(1-\sum_{j=1}^{M} z_{j}^{2}\right)}
$$

Under the null hypothesis of random localization of the plants, the expected value of the measure is zero, with any positive value of the index interpreted as evidence of localization. Testing the statistical significance of the index indicates whether a sector's distribution of activity across locations is significantly concentrated or dispersed in a statistical sense. ${ }^{9}$ The proposed index has three desirable properties: [i] it does not take on the value of zero if employment is uniformly spread across space (as is the case with most of the traditional indicators) "[...] ... but instead if employment is only as concentrated as it would be expected to be if the plants in the industry had chosen locations by throwing darts at a map"; [ii] the index is comparable across industries in which the size distribution of firms differs; [iii] it allows meaningful comparisons regardless of differences in the level of geographic aggregation at which employment data for the respective industries are available (Ellison and Glaeser, 1997: p. 890 and p. 900). Although the index provides us with a useful description of agglomeration, it is inherently a-spatial. Every region is treated as an isolated island, and its position in space relative to other regions is not taken into account. In what follows

\footnotetext{
${ }^{8}$ For details on the derivation of the measure of geographical concentration, see Ellison and Glaeser (1997).

${ }^{9}$ As shown in Ellison and Glaeser (1997) and Maurel and Sédillot (1999), the variance of the estimator under the null hypothesis of no spillovers $\gamma=0$ is given by:$$
\operatorname{var}\left(\hat{\gamma}_{E G}\right)=\frac{2(1-H)^{2}}{\left(1-\sum_{i=1}^{M} x_{i}^{2}\right)} H^{2}\left(\sum_{i=1}^{M} x_{i}^{2}-2 \sum_{i=1}^{M} x_{i}^{3}+\left(\sum_{i=1}^{M} x_{i}^{2}\right)^{2}\right)-\sum_{j=1}^{N} z_{j}^{4}\left(\sum_{i=1}^{M} x_{i}^{2}-4 \sum_{i=1}^{M} x_{i}^{3}+3\left(\sum_{i=1}^{M} x_{i}^{2}\right)^{2}\right)
$$

The result can be used to perform a $t$-test comparing the value of the index with twice its standard deviation, which, under the assumption of normality, is a test at the $5 \%$ significance level. Significant values of the test indicate that the observed degree of concentration deviates significantly from a situation of random location of the firms.
} 
we analyze the geographical concentration in the manufacturing and service sectors in Italy for the years 1991 and 2001.

\section{The concentration of 2-digit manufacturing and service industries in Italy}

We computed the index $\hat{\gamma}_{E G}$ for each of the 2-digit manufacturing and service industries in our dataset. ${ }^{10}$ Previous studies have observed that the scale of the territorial units may influence the degree to which industries are found to be concentrated (Ellison and Glaeser, 1997; Maurel and Sèdillot, 1999; Lafourcade and Mion, 2007; Alecke et al., 2006). Table 1 illustrates the average value of $\gamma_{E G}$ in the manufacturing and service sectors for the years 1991 and 2001. The results show that there is a strong tendency of the index to increase at the higher level of aggregation of the territorial units. A reason for this may be spatial autocorrelation between local labour systems, which the index is not able to capture at the lower geographical level because of its "a-spatial" property discussed above. Thus, computing the Ellison and Glaeser index at a higher level of spatial aggregation will partly internalize positive spatial autocorrelation, leading to a higher concentration. Notice that this result is in contrast with the previous findings on the relationships between other measures of concentration and the problem of scale (see Arbia, 1989).

\section{[Table 1 about here]}

As a first observation, we note that whereas manufacturing has been spreading out, service activities have become increasingly clustered. A potential explanation is falling transport costs. Due to their non-tradable nature, services have traditionally spread out. The drop in transport costs is now allowing them to agglomerate. Manufacturing, however, already became highly concentrated during the last centuries (Kim, 1995; Glaeser, 1998); the more recent fall in transport costs has been weakening the benefits from agglomeration, leading manufacturing activity to spread out. The different concentration patterns across manufacturing and service sectors may also be due to technological changes. Carlino (1985), for instance, argues that the slicing up of the value chain into different stages has allowed manufacturing firms to relocate certain activities to less dense areas. As for the rising concentration of services in cities, high-tech services are experiencing an increasing need to be close to specialized workers. Service sector activities concentrate in large cities because large home markets make it possible to both economize on the cost of moving people and to achieve economies of scale. Moreover, while in 1991 the concentration in the service sector is

\footnotetext{
${ }^{10}$ Information on the values of the index for the complete set of sectors is available from the authors upon request.
} 
lower than in the manufacturing sector for all three levels of spatial aggregation, a different pattern is observed in 2001.

We now turn to the geographical concentration of the 15 most localized 2-digit industries across LLSs which are discussed in Table 2. As an initial step, we are interested in analyzing how industrial agglomeration evolved throughout the period. Among the 15 most localized industries, only the Tobacco Industry, Manufacture of Non-Metal Products, and Manufacture of Other NonMetallic Mineral Products are not among the most concentrated industries in both years. In all other cases, the same industries appear to be among the most concentrated both in 1991 and in 2001. The stability in concentration level observed in most Italian industries is a pattern also found in other countries (Dumais et al., 2002, for the US; Devereux et al., 2004, for the UK; Alonso-Villar et al., 2004, for Spain). Among the most concentrated industries is the Manufacture of Motor Vehicles, although the degree of concentration has noticeably declined in the 1990s. The result is not surprising, considering that the larger part of the production of motor vehicles in Italy is carried by one single firm (FIAT) which concentrates its activity in a small number of plants (i.e. Turin in Piemonte, Termini Imerese in Sicily and Melfi in Basilicata). ${ }^{11}$ Considering the sectors with the highest degree of concentration, we can identify two distinct groups of industries; both groups are characterized by the strong presence of firms of small and medium size. The first group includes a number of high-tech industries such as Manufacture of Office Machinery and Computers, Manufacture of Chemicals, Manufacture of Radio, Television, and Communication Equipment. As pointed out in Maggioni (2002), Italian high-tech clusters are somehow different from the ones existing in other countries. In general, small and medium-sized firms that are characterized by a lower level of technology adoption compose them. In a second group, we find traditional activities in which the weight of small and medium-sized enterprises is also very high, such as Manufacture of Textile and Tanning and Dressing of Leather. These are industries operating in a well-defined area of the country: the so-called "Third Italy". ${ }^{12}$ In a number of sectors where small firms predominated, groups of firms which are clustered together in specific regions seemed to be able to grow rapidly, to develop niches in export markets and to offer new employment opportunities.

Among the service industries, Research and Development, Computer and Related Activities and Insurance and Pension Funding show the highest level of concentration. Different from manufacturing, these industries tend to concentrate in dense urban areas, where a pool of high-

\footnotetext{
${ }^{11}$ However, in the last years, thanks to the financial and fiscal incentives available to the Objective 1 regions, FIAT has decentralized part of its production in the southern regions of Italy.

${ }^{12}$ The concept of the Third Italy was introduced in the late 1970s. At that time, it became apparent that little economic progress was realized in the South (Second Italy), and that the traditionally rich Northwest (First Italy) was facing a deep crisis, while in contrast the Northeast and centre of Italy showed fast growth.
} 
qualified workers is available, and where the high costs associated with the services offered may be divided among a longer number of potential customers.

[Tables 2 about here]

\section{Spatial dependencies in the distribution of economic activities in Italy}

\section{Global spatial dependence}

The concentration index employed so far provides useful information about the extent to which industries in Italy are concentrated in a limited number of areas, but does not take into consideration whether those areas are close together or far apart. Two industries may appear equally geographically concentrated, while one is located in two neighbouring regions, and the other splits between the northern and the southern part of the country. Every region is treated as an isolated island, and its position in space relative to other regions is not taken into account. As such, it still suffers from the same shortcoming as previous indices of geographical concentration (Arbia, 2001).

Traditional measures of concentration, including the Ellison and Glaeser index, are inherently a-spatial. As a result, the same degree of concentration can be compatible with very different localization schemes. Alternatively, as proposed in Arbia (2001), one can derive a composite index in which both a-spatial measures of concentration and spatial measures - able to discriminate between geographical patterns - are simultaneously considered. A number of empirical studies explicitly consider the relative position of the regions in the space. Midelfart-Knarvik et al. (2004) propose an index of spatial separation that takes into account distances between locations. Lafourcade and Mion (2007) quantify the degree of spatial agglomeration in the Italian manufacturing industries using a measure of spatial agglomeration where proximity is expressed in terms of minimum road distances among pairs of locations. A technique that falls within the range of Exploratory Spatial Data Analysis (ESDA) is employed in Guillain and Le Gallo (2006) to some French data related to Paris and to its surroundings in order to investigate the employment location patterns of manufacturing and services sectors.

Once we recognize that regions are not isolated islands, we may be interested in using a measure able to take into account spatial autocorrelation among geographical units. Spatial autocorrelation is present when the values of one variable observed at nearby locations are more similar than those observed in locations that are far apart. More precisely, positive spatial autocorrelation occurs when high or low values of a variable tend to cluster together in space and negative spatial autocorrelation when high values are surrounded by low values and vice-versa. 
The literature has provided a number of indicators to distinguish amongst various cases of spatial dependence, like the Moran's I index of spatial autocorrelation (Moran, 1950) and the Getis and Ord statistics of local spatial association (Getis and Ord, 1992). We use the former in this paper.

In what follows we will rely on a measure of concentration which considers explicitly the relative position of the areas over the space. The point of departure is the commonly used measure of regional industrial concentration termed "Location Quotient" (LQ) and defined in Kim (1995) as: $^{13}$

$$
L Q_{s, i}=\frac{e_{s, i} / \sum_{i} e_{s, i}}{\sum_{s} e_{s, i} / \sum_{i} \sum_{s} e_{s, i}}
$$

In Equation (2) the numerator measures the share of employment in sector $s$ in region $i$ with respect to the total employment in Italy in sector $s$, and the denominator is the share of total employment in region $i$ with respect to the total employment in Italy.

The Moran's I coefficients of spatial autocorrelation are then obtained by using the Location Quotient relative to each sector and each location as the basis for computations. To allow comparisons between different regions, the Moran's I coefficients are expressed in standardized scores. Formally, for each variable of interest, the Moran's $I$ equals:

$$
I=\frac{N}{\sum_{i=1}^{n} \sum_{j=1}^{n} w_{i j}} \frac{\sum_{i=1}^{n} \sum_{j=1}^{n} w_{i j}\left(x_{i}-\bar{x}\right)\left(x_{j}-\bar{x}\right)}{\sum_{i=1}^{n}\left(x_{i}-\bar{x}\right)^{2}}
$$

where $N$ is the total number of observations, $x_{i}$ and $x_{j}$ are the observed values of the location quotient as defined in expression (2) for the locations $i$ and $j$ (with mean $\bar{x}$ ), and the first term is a scaling constant. This statistic compares the value of a continuous variable at any location with the value of the same variable at surrounding locations. The spatial structure of the data is formally expressed in a spatial weight matrix W (Cressie, 1991; Anselin, 1988) with generic elements $w_{i j}$ (with $i \neq j$ ). ${ }^{14}$ In the rest of the paper we will employ a weight matrix defined by a first-order

\footnotetext{
${ }^{13}$ The Location Quotient is frequently adopted by the Italian Statistical Office as a measure of geographic concentration in its official reports. For an alternative methodology to detect spatial patterns in the distribution of the Italian manufacturing industry see Lafourcade and Mion (2007).

${ }^{14}$ By convention, the diagonal elements of the weights matrix are set to zero.
} 
contiguity, such that $w_{i j}=1$ if region $i$ and $j$ are neighbours and $w_{i j}=0$ otherwise. ${ }^{15}$ The results of the Moran's I statistics of the 15 more agglomerated industries in 1991 and 2001 are listed in Tables 3. A first remarkable feature is that over the years, with the exception of few sectors, the 15 highest positions in the ranking have been occupied by the same industries. A feature that is very similar to what we have found before using the measure proposed by Ellison and Glaeser. Considering the manufacturing sector, a first observation is that patterns of spatial dependence tend to emerge in traditional sectors characterized by the use of basic technologies like Tanning of Dressing of Leather, Manufacture of Textile, and Manufacture of Metal Products. Traditionally, these are sectors in which operate firms of small and medium size localized in well-defined industrial clusters in the Northern and Central part of the country (Emilia Romagna, Tuscany and Marche). ${ }^{16}$

The above discussions demonstrate that the degree of concentration varies across sectors and that a similar degree of geographical concentration (as indicated by the EG index) may be associated to different degrees of spatial dependence (as indicated by Moran's I statistic). As a further step, we can jointly consider the results produced by the Ellison and Glaeser measure of geographical concentration and the Moran's I measure of spatial dependence described above. Similarly to Guillain and Le Gallo (2006) and Arbia (2001), we can identify three different patterns in the distribution of economic activities where either or both geographical concentration and spatial dependence occur: (i) high concentration \& low spatial dependence, (ii) high concentration $\&$ high spatial dependence, (iii) low concentration \& high spatial dependence.

We find three sectors in which high concentration and a low degree of spatial dependence coexist. This means that these industries concentrate their activity in a small number of areas that are not close to each other. These are Manufacture of Motor Vehicle, Manufacture of Office Machinery and Manufacture of Chemicals. These are sectors with firms in which economies of scale may be reached only by increasing their plant size and concentrating the production in a small number of locations (for example, motor vehicle industry in Turin and the chemicals industry in the region Lazio). However, during the 1990s the picture slightly changes and we observe a decline in the degree of spatial concentration of the sectors mentioned above. One possible explanation is that due to a number of financial and fiscal incentives to promote the economic development of lagging regions in Italy, these industries have decided to decentralize their activities.

\footnotetext{
${ }^{15}$ We checked for the robustness of the results reported in the paper which are based on the use of a firstorder contiguity matrix. More specifically, we repeated the exercise using spatial weights matrices based on the inverse distance and the squared of the inverse distance between pairs of locations (with different threshold levels). The results are comparable and are available from the authors upon request.

${ }^{16}$ However, we observe that the spatial pattern in these sector tend to be stronger at the lower level of LLS than - for instance - at the level of NUTS3 regions. Results for NUTS2 and NUTS3 regions are available from the authors upon request.
} 
Only two industries, Tanning and Dressing of Leather and Manufacture of Textile are highly concentrated and at the same time strongly agglomerated. Concentration may occur because these are sectors that in Italy are traditionally located in well-defined administrative areas (Marche for the leather industry and Toscana for the textile). If we then consider that production in these sectors takes place over a number of industrial districts that are close to each other, we may explain why we observe also a high level of spatial dependence. The picture is similar in both years, reinforcing the belief that we are facing episodes of territorial industrial success that are not temporary. This is a feature that reinforces the central role played by the industrial districts in Italy on promoting regional economic development and high standards of productivity.

In the last group we find those industries for which the distribution of employment is rather spread over the country, although similar values tend to cluster together. A remarkable feature that emerges is that the majority of industries in this group are services. Other Wholesale, Hotels and Restaurants, and Real Estate Activities represent the three extreme cases.

[Table 3 about here]

\section{Local spatial patterns in the distribution of economic activities in Italy.}

The traditional Moran's I measure of spatial autocorrelation that we used so far is a global measure. It captures the overall spatial pattern in the data and summarizes it in a single statistic. When studying the spatial distribution of production activity in space, it may be the case that there is significant autocorrelation only for a subset of regions. A positive measure of global autocorrelation captures the existence of both high-value clustering and low-value clustering, while a negative autocorrelation captures the juxtaposition of high-values next to low-values. In other words, only one dominant type of autocorrelation can be detected. If two structures, such as high-value clustering and low-value clustering, coexist, Moran's $I$ cannot distinguish them (Zhang and Lin, 2007). In contrast, local indicators of spatial association (or LISA) are specifically designed to find evidence of local spatial patterns in the empirical data. These indicators allow for the decomposition of global indicator, such as Moran's $I$, into the contribution of each individual observation (Anselin, 1995). LISA, when coupled with other exploratory spatial data-analysis tools such as Moran's $I$ scatter plot, is able to detect local spatial associations, such as high-value clusters, low-value clusters, and negative autocorrelations. In what follows, we measure local spatial dependence using the local version of the Moran's I statistic described before. The local Moran's I yields a measure of spatial autocorrelation for each individual location and is designed to test whether the distribution of values around that specific location deviates from spatial randomness. Local indicators of spatial 
association can be used for the detection of significant local spatial clusters (also called "hot spots") as well as for diagnostics of local instability, significant outliers and spatial regimes. ${ }^{17}$ The local Moran statistic for an observation $i$ is defined as (Anselin, 1995):

$$
I_{i}=z_{i} \sum_{j \neq i} w_{i j} z_{j}
$$

For ease of interpretation, the weights $w_{i j}$ are row standardized and by convention $w_{i i}=0$. As before, the spatial ordering is defined using a first-order contiguity matrix between functional areas. The local Moran's I coefficients are obtained by using the Location Quotients as the basis for computations. We illustrate the results using a cartographic representation - the local Moran's $I$ significance map - in which the significant values of the local Moran are classified as: $\mathrm{HH}$ for locations with high levels of the location quotient for a specific sector surrounded by regions with high levels of the location quotients; LL for locations with low levels surrounded by locations where the location quotients are also low; HL for locations with high values surrounded by locations with low values, and LH for locations with low values surrounded by locations with high values. While the first two typologies (namely HH and LL) suggest clustering of similar values, the last two situations (HL and $\mathrm{LH}$ ) capture the presence of regional outliers in the spatial distribution of economic activities. In what follows, we comment on the results for the following sectors: Manufacture of Textile, Tanning and Dressing of Leather, Manufacture of Radio, Television and Communication Equipments, Manufacture of Medical, Precision and Optical Instruments and Research and Development. ${ }^{18}$ Figures 1-5 illustrate the results. In each map, the figure on the left displays the spatial distribution of the location quotients - as defined in equation (2) - in the sectors listed above, while the figure on the right plots the local Moran's I significance map. It is interesting to consider the two maps jointly in order to fully understand the value of the use of local indicators. In fact, a pure inspection of the spatial patterns of the location quotients is not able to capture the existence of production clusters. Once we inspect the local Moran significance map we can easily identify significant industrial local clusters. We find that, in most cases, these clusters correspond to some of the industrial districts identified in Italy by the National Statistical Office. We strongly believe that such an approach is very useful for local policy authorities interested in identifying new industrial clusters and in testing the performance of pre-existing industrial districts. In the first two sectors - Manufacture of Textile and Tanning and Dressing of Leather - we find mostly firms of

\footnotetext{
17 Amongst others, we find applications of local indicators of spatial association for the analysis of the distribution of regional income and structural funds in Europe (Dall'Erba, 2005), and for the study of local agglomeration patterns in Paris and its surroundings (Guillain and Le Gallo, 2006).

${ }^{18}$ The results for the other sectors are available from the authors upon request.
} 
small and medium size belonging to the traditional manufacturing sector. ${ }^{19}$ In both sectors the production tends to be organized in industrial districts. ${ }^{20}$ Within the same district, companies establish close relationships which contribute to the creation of the competitive success: on the one hand strong competition stimulates product innovation; on the other hand, proximity and a high level of specialization allow for a continuous transmission of knowledge. This produces not only a high level of flexibility, but also enables the economies of scale typically found in large companies to be achieved through productive integration. The sector Manufacture of Textile concentrates in the centre-north of Italy, mostly in the areas of Biella, Carpi and Prato. Biella is a major world centre of the wool industry since the early 19th century, and it is further specialised in the mechanic-textile sector. The Prato wool district has a tradition dating back to the Middle Ages. The Tanning and Dressing of Leather industry exhibits a strong tendency to cluster over a small number of territorial units, in particular in the regions Tuscany and Marche. A cluster in this industry is also present in the south of Italy in the footwear industrial district of Casarano (in the region Apulia).

[Figures 1 and 2 about here]

The second group of industries - Manufacture of Radio, Television and Communication Equipment and Manufacture of Medical Precision and Optical Instruments - consists of a variety of firms of different sizes which adopt technologically sophisticated production systems. We find evidence of a significant cluster in the sector Manufacture of Radio, Television and Communication Equipment in the area surrounding Rome. In the eastern zone of the city (the Tiburtina area) prominent aerospace industries are present as well as small and medium-sized enterprises. Moreover, a high concentration of company service providers and the presence of centres of excellence such as the Castel Romano technological centre, the Tiburtino technological centre, the Audiovisual centre and the Information and Communication Technologies centre, make the province of Rome to play a leading role in Italy in the high-tech sector. Figure 3 highlights the presence of an outlier cluster in the south of Italy, in the region Sicily. This is the technological district of Catania. The origin of the Catania Technological District is closely linked to the history of a leading company in semiconductor solutions for microelectronic applications. The Catania area hosts nowadays a number of multinational giants in the telecommunication sector (such as Nokia, IBM, and

19 The traditional sectors consist of the low-technology manufacturing and the medium-low technology manufacturing.

${ }^{20}$ In Italy, the district model consists of a high concentration of small and medium-sized firms, specialized in the production of a specific item and grouped together in the same territorial area. For additional information on industrial districts in Italy and for an overview of their history and main production activities, see www.distretti.org. 
Telespazio). Moreover, alongside these large companies, a number of well established local companies, as well as relatively new ones, have sprung up and thrived in the district's fertile ground in the satellite telecommunications, ophthalmic and pharmaceutical products, and precision engineering.

[Figure 3 about here]

The production in the Manufacture of Medical, Precision and Optical Instruments is highly clustered in Northern Italy, in the region Veneto. The extension of this sector coincides with that of the Province of Belluno. The District specialises in all sorts of eyewear products. The evolution of the spectacle district in Belluno offers an interesting history. It evolved from a system in which small and large firms operate together to a system where the production is concentrated in a small number of large firms. Until the first half of the 1990s the stable growth in this sector has been determined by the development of a number of large industrial groups and the growth of smaller manufacturers. In the 1990s the district development model drastically changed. Without the advantages deriving from the repeated devaluation of the Italian currency, the larger firms were forced to select their sub-contractor more strictly, and in some cases to move less specialized stages of the production to countries where the cost of the labour was lower. As a consequence " [...] the gap between large and small firms widened. The former continued their rapid growth, absorbing the most qualified human resources from the local labour market. In contrast, the latter not only suffered a contraction in orders, but also witnessed to a gradual deterioration of external economies, regarding inter-firm relations, human capital, services, collective goods and state institutions" (Corò and Grandinetti, 2001, p. 193).

[Figure 4 about here]

Figure 5 illustrates the spatial distribution of the location quotients and the resulting local Moran's $I$ significance map in the sector Research and Development. A long-standing weakness of the Italian science system is the low level of investments in R\&D activities, compared with the position of the country's economic system among those of the most industrialized nations. A major objective of research policies is to shift the balance between public and private effort in scientific and technological research. Indeed, while the public investment in $R \& D$ is comparable with that in other industrialized countries, the private expenditure on research is relatively low (European Commission, 2006). A successful attempt to fill the gap between private and public investments in R\&D is constituted by the High-Tech Network project launched in the region Emilia Romagna. By 
looking at the figure on the left in Figure 5, we find a significant cluster of employment in the R\&D sector in the local labour system of Bologna. This city is indeed a leader in the Emilia Romagna High-Tech Network, with more than twenty industrial research laboratories, about ten innovation centres and three innovation parks. A second cluster emerges in the region Lazio, which is the Italian region with the highest expenditure in R\&D in terms of GDP. ${ }^{21}$ The region Lazio is a pole of excellence of advanced scientific and technological research in Italy, due to the extensive network in the area of public and private research universities and centres, due also to the presence here of the largest national companies operating in the aerospace sector and to a well-established network of small and medium-sized companies in the sector (see our discussion for the Manufacture of Radio, Television and Communication Equipment sector). The local Moran's I significance map reveals the presence of two local clusters, in the local labour system of Trento (in the north-east part of Italy) and in the local labour system of Policoro and Pisticci in the southern region of Basilicata, where a number of public research centres are located (for example, those belonging to the ENEA the Italian National Agency for New Technologies, Energy and the Environment - and to the CNR, the Italian National Research Council).

[Figure 5 about here]

\section{Conclusions}

In this paper we contribute to the empirical literature on the spatial distribution of economic activities by taking spatial dependence among territorial units explicitly into account. Using data for Italy, we apply an approach that considers simultaneously geographical concentration and spatial dependence to characterize the spatial distribution of industries. We look at manufacturing industries, as well services. We observe that large differences prevail in the geographical concentration of production across sectors. In particular, we observe that, in the period under study, concentration has substantially declined in the manufacturing industry, while service industries have become increasingly concentrated. In the manufacturing sector, the industries that show up as being the most concentrated are those belonging to the traditional sectors and the high-tech industries. Among the service industries, Research and Development and Insurance and Pension Funding show the highest level of concentration. However, the results provided by the Ellison and Glaeser index of geographical concentration do not consider the spatial structure inherent in the data. Hence, we investigate the spatial patterns in the distribution of economic activities in Italy, taking explicitly

\footnotetext{
${ }^{21}$ Source: Eurostat, Regional Statistics. Available at http://ec.europa.eu/eurostat.
} 
into account spatial dependencies, both at the global and at the local level. We compute Location Quotients to measure the concentration in the production in each sector and in each location in Italy and then we use this measures as the basis for computing Moran's I measures of global and local spatial autocorrelation. In particular, local measures of spatial autocorrelation revealed us the presence of well defined clusters of economic activities (for example, in the textile industry, and in research and development). Industrial clusters at the local level are considered one of the main engines of regional development.

A number of aspects were not taken into consideration in the present work and remain the subject of future development. It might be interesting to study the distribution of economic activities in Italy at a lower level of sectoral aggregation. For some sectors it has been found that a lower level of aggregation is more suitable to detect episodes of spatial clustering (Lafourcade and Mion, 2007). Another interesting topic would be to investigate in more depth the forces that can explain the observed patterns of agglomeration. From a measurement perspective, we follow the tradition initiated by Arbia (2001) in which the spatial characteristics of concentration are invstigated by simultaneously considering the a-spatial characteristics and a spatial concentration index. However, recent developments suggest that it is possible to consider both characteristics simultaneously in one single summary index as it is indicated by Arbia and Piras (2007). This represents a further point of departure for future developments in this field.

\section{References}

Alecke B., Alsleben C., Scharr F. and Untiedt G. (2006) Are there really high-tech clusters? The geographic concentration of German manufacturing industries and its determinants, Annals in Regional Science 40: 19-42.

Alonso-Villar O., Chamorro-Rivas J.M. and González-Cerdeira X. (2004) Agglomeration economies in manufacturing industries: the case of Spain, Applied Economics 36 (18): 2103-16.

Anselin L. (1988) Spatial Econometrics: Methods and Models, Kluwer: Dordrecht.

Anselin L. (1995) Local indicators of spatial association - LISA, Geographical Analysis 27: 93115.

Arbia G. (1989) Spatial Data configuration in Statistical Analysis of Regional Economics and Related Problems, Kluwer: Dordrecht.

Arbia G. (2001) The role of spatial effects in the empirical analysis of regional concentration, Journal of Geographical Systems 3: 271-81.

Arbia G. and Piras G. (2007) A measure of spatial concentration, paper presented at the North American Meetings of the Regional Science Association International, Savannah, November 2007.

Arbia G. and Espa G. (1996) Statistica Economica Territoriale, Cedam: Padua.

Arbia G., Espa G. and Quah D. (2007) A class of spatial econometric methods in the empirical analysis of clusters of firms in the space, University of Trento Discussion Paper no. 5. 
Braunerhjelm P. and Johansson D. (2003) The determinants of spatial concentration: the manufacturing and service sectors in an international perspective, Industry and Innovation 10 (1): 41-63.

Carlino G.A. (1985) Declining city productivity and the growth of rural regions: a test of alternative explanations, Journal of Urban Economics 18: 11-7.

Combes P. and Overman H.G. (2004) The spatial distribution of economic activities in the European Union, in: J.V. Henderson and J.F. Thisse (eds), Handbook of Regional and Urban Economics, volume 4: 2845-909, Elsevier: Amsterdam.

Corò G. and Grandinetti R. (2001) Industrial district responses to the network economy: vertical integration versus pluralist global exploration, Human Systems Management 20 (3): 18999.

Cressie N.A.C. (1991) Statistics for Spatial Data, Wiley: New York.

Dall'Erba S. (2005) Distribution of regional income and regional funds in Europe 1989-1999: an exploratory spatial data analysis, Annals in Regional Science 39 (1): 121-48.

Devereux M.P., Griffith R. and Simpson H. (2004) The geographic distribution of production activity in the UK, Regional Science and Urban Economics 34 (5): 533-64.

Dumais G., Ellison G. and Glaeser E.G. (2002) Geographic concentration as a dynamic process, Review of Economics and Statistics 84 (2): 193-204.

Duranton G. and Overman H.G. (2005) Testing for localization using micro-geographic data, Review of Economic Studies 72 (4): 1077-106.

Ellison G. and Glaeser E.L. (1997) Geographic concentration in U.S. manufacturing industries: a dartboard approach, Journal of Political Economy 105 (5): 899-927.

European Commission (2006) ERAWATCH Research inventory report for Italy, available at www.cordis.europa.eu/erawatch.

Getis A. and Ord J.K. (1992) The analysis of spatial association by use of distance statistics, Geographical Analysis 24 (3): 189-206.

Glaeser E.L. (1998) Are cities dying? Journal of Economic Perspectives 12 (2): 139-60.

Guillain R. and Le Gallo J. (2006) Measuring agglomeration: an exploratory spatial analysis approach applied to the case of Paris and its surroundings, REAL Discussion Papers, no. 06-T-10, University of Illinois at Urbana Champaign.

Hanson G. (1998) North American integration and industry location, Oxford Review of Economic Policy 14: 401-19.

Jacobs J. (1960) The Economy of Cities, Vintage: New York.

Kim S. (1995) Expansion of markets and the geographical distribution of economic activities: the trends in the U.S. manufacturing industries, 1860-1987, Quarterly Journal of Economics 110 (4): 881-908.

Kim S. (1999) Urban development in the United States 1690-1990, NBER Working Paper, no. 7120, Cambridge, MA.

Krugman P. (1991) Geography and Trade, MIT Press: Cambridge.

Lafourcade M. and Mion G. (2007) Concentration, agglomeration and the size of plants, Regional Science and Urban Economics 37 (1): 46-68.

Maggioni M.A. (2002) Clustering Dynamics and the Location of High-tech Firms, Springer: Heidelberg.

Marcon E. and Puech F. (2003) Evaluating the geographic concentration of industries using distance-based measures, Journal of Economic Geography 3: 409-28.

Marshall A. (1890) Principles of Economics, MacMillan: London.

Maurel F. and Sédillot B. (1999) A measure of the geographic concentration in French manufacturing industries, Regional Science and Urban Economics 29: 575-604.

Midelfart-Knarvik K.H., Overman H.G., Redding S.G. and Venables A.G. (2004) The location of European industry, in: A. Dierx, F. Ilzkovitz and K. Sekkat (eds), European Integration and the Functioning of Product Markets, Edward Edgar Publishing: Cheltenham. 
Moran P.A.P. (1950) Notes on continuous stochastic phenomena, Biometrika 37: 17-23.

Pagnini M. (2003) Misura e determinanti dell'agglomerazione spaziale nei comparti industriali in Italia. In Temi di Discussione, Bank of Italy, no. 452, Rome.

Pellegrini G. (2004) Modelli di diffusione territoriale dell'industria manifatturiera in Italia, in: F. Signorini (ed.) Economie locali, modelli di agglomerazione e apertura internazionale, Bank of Italy, Rome.

Quah D. and Simpson H. (2003) Spatial cluster empirics, London School of Economics Working Paper Series.

Ruiz-Valenzuela, J., Moreno-Serrano, R. and Vaya-Valcarce, E. (2007) Has concentration evolved similarly in manufacturing and services? A sensitivity analysis, Documents de Treball, No. 2007/8, Institut de Recerca de Economia Aplicada, Universitat de Barcelona, Spain.

Zhang, T. and Lin, G. (2007) A decomposition of Moran's I for clustering detection, Computational Statistics \& Data Analysis, 51(12): 6123-37. 


\section{Tables and Figures}

Table 1. Average values of Ellison-Glaeser index $\left(\gamma_{E G}\right)$ in 1991 and 2001 at different levels of spatial aggregation

\begin{tabular}{rrrrrrr}
\hline & \multicolumn{2}{c}{ LLSs } & \multicolumn{2}{c}{ NUTS3 (provinces) } & \multicolumn{2}{c}{ NUTS2 (regions) } \\
\hline & $\mathbf{1 9 9 1}$ & $\mathbf{2 0 0 1}$ & $\mathbf{1 9 9 1}$ & $\mathbf{2 0 0 1}$ & $\mathbf{1 9 9 1}$ & $\mathbf{2 0 0 1}$ \\
\hline \multirow{3}{*}{$\begin{array}{r}\text { manufacturing } \\
\text { service }\end{array}$} & 0.024 & 0.015 & 0.027 & 0.023 & 0.042 & 0.041 \\
& 0.018 & 0.024 & 0.018 & 0.037 & 0.020 & 0.034 \\
\hline
\end{tabular}

Table 2. Ellison-Glaeser index $\left(\gamma_{E G}\right)$ for 15 most concentrated industries in 1991 and 2001

\begin{tabular}{|c|c|c|c|c|c|c|c|}
\hline 2-digit & sector & $\begin{array}{l}\text { Technological } \\
\text { intensity }^{\mathrm{a}}\end{array}$ & $\begin{array}{l}\text { Knowledge } \\
\text { intensive }^{\mathrm{b}}\end{array}$ & $\begin{array}{c}\gamma_{E G} \\
1991\end{array}$ & $\begin{array}{c}\text { Rank } \\
1991\end{array}$ & $\begin{array}{c}\gamma_{E G} \\
2001\end{array}$ & $\begin{array}{c}\text { Rank } \\
2001\end{array}$ \\
\hline 34 & Manufacture of motor vehicles & medium-high & no & 0.145 & 1 & 0.061 & 3 \\
\hline 30 & $\begin{array}{l}\text { Manufacture of office machinery and } \\
\text { computers }\end{array}$ & high & no & 0.131 & 2 & - & - \\
\hline 61 & Water transport & - & yes & 0.087 & 3 & 0.072 & 2 \\
\hline 66 & Insurance and pension funding & - & yes & 0.063 & 4 & 0.073 & 1 \\
\hline 73 & Research and development & high & yes & 0.047 & 5 & 0.026 & 7 \\
\hline 24 & $\begin{array}{l}\text { Manufacture of chemicals and } \\
\text { chemical products }\end{array}$ & medium-high & no & 0.034 & 6 & 0.028 & 6 \\
\hline 32 & $\begin{array}{l}\text { Manufacture of radio, television and } \\
\text { communications }\end{array}$ & high & no & 0.029 & 7 & 0.021 & 9 \\
\hline 17 & Manufacture of textiles & low & no & 0.029 & 8 & 0.034 & 4 \\
\hline 22 & Publishing, printing and reproduction & low & no & 0.026 & 9 & - & - \\
\hline 19 & Tanning and dressing of leather & low & no & 0.026 & 10 & 0.034 & 5 \\
\hline 72 & Computer and related activities & high & yes & 0.016 & 11 & 0.022 & 8 \\
\hline 27 & Manufacture of basic metals & medium-low & no & 0.015 & 12 & 0.016 & 11 \\
\hline 23 & $\begin{array}{l}\text { Manufacture of coke, refined } \\
\text { petroleum products }\end{array}$ & medium-low & no & 0.014 & 13 & - & - \\
\hline 36 & Manufacture of furniture & medium-low & no & 0.013 & 14 & 0.016 & 13 \\
\hline 37 & $\begin{array}{l}\text { Manufacture of other transport } \\
\text { equipment }\end{array}$ & medium-high & no & 0.013 & 15 & 0.014 & 15 \\
\hline 22 & $\begin{array}{l}\text { Publishing. printing, and } \\
\text { reproduction }\end{array}$ & low & no & - & - & 0.016 & 10 \\
\hline 16 & Manufacture of tobacco products & low & no & - & - & 0.016 & 12 \\
\hline 26 & $\begin{array}{l}\text { Manufacture of other non-metallic } \\
\text { mineral products }\end{array}$ & medium-low & no & - & - & 0.015 & 14 \\
\hline
\end{tabular}


Table 3. Moran's I for 15 most spatially autocorrelated industries in 1991 and 2001

\begin{tabular}{|c|c|c|c|c|c|c|c|}
\hline 2-digit & sector & $\begin{array}{l}\text { Technological } \\
\text { intensity }^{\mathrm{a}}\end{array}$ & $\begin{array}{l}\text { Knowledge } \\
\text { intensive }^{\mathrm{b}}\end{array}$ & $\begin{array}{c}\text { Moran's } I \\
1991\end{array}$ & $\begin{array}{c}\text { Rank } \\
1991\end{array}$ & $\begin{array}{l}\text { Moran's I } \\
2001\end{array}$ & $\begin{array}{l}\text { Rank } \\
2001\end{array}$ \\
\hline 52 & Other wholesale & - & no & 0.526 & 1 & 0.540 & 2 \\
\hline 55 & Hotels and restaurants & - & no & 0.499 & 2 & 0.448 & 4 \\
\hline 19 & Tanning and dressing of leather & low & no & 0.489 & 3 & 0.463 & 3 \\
\hline 29 & $\begin{array}{l}\text { Manufacture of machinery and } \\
\text { equipment }\end{array}$ & medium-high & no & 0.418 & 4 & 0.396 & 5 \\
\hline 18 & Manufacture of wearing apparel & low & no & 0.408 & 5 & 0.352 & 7 \\
\hline 70 & Real estate activities & - & yes & 0.391 & 6 & 0.619 & 1 \\
\hline 45 & Construction & - & no & 0.381 & 7 & - & - \\
\hline 28 & $\begin{array}{l}\text { Manufacture of fabricated metal } \\
\text { products }\end{array}$ & medium-low & no & 0.355 & 8 & 0.352 & 6 \\
\hline 50 & $\begin{array}{l}\text { Sale, maintenance and repair of } \\
\text { motor vehicles }\end{array}$ & - & no & 0.303 & 9 & 0.304 & 9 \\
\hline 17 & Manufacture of textiles & low & no & 0.261 & 10 & 0.205 & 15 \\
\hline 36 & Manufacture of furniture & medium-low & no & 0.254 & 11 & 0.260 & 10 \\
\hline 51 & $\begin{array}{l}\text { Wholesale trade and commission } \\
\text { trade }\end{array}$ & - & no & 0.230 & 12 & 0.317 & 8 \\
\hline 33 & $\begin{array}{l}\text { Man. of medical, precision and } \\
\text { optical instruments }\end{array}$ & high & no & 0.224 & 13 & 0.256 & 11 \\
\hline 31 & $\begin{array}{l}\text { Manufacture of electrical machinery } \\
\text { and apparatus }\end{array}$ & medium-high & no & 0.196 & 14 & - & - \\
\hline 72 & Computer and related activities & high & yes & 0.184 & 15 & 0.206 & 14 \\
\hline 71 & Renting of machinery and equipment & - & yes & - & - & 0.255 & 12 \\
\hline 67 & $\begin{array}{l}\text { Activities auxiliary to financial } \\
\text { intermediation }\end{array}$ & - & no & - & - & 0.239 & 13 \\
\hline \multicolumn{8}{|c|}{${ }^{\mathrm{b}}$ classification EUROSTAT } \\
\hline
\end{tabular}



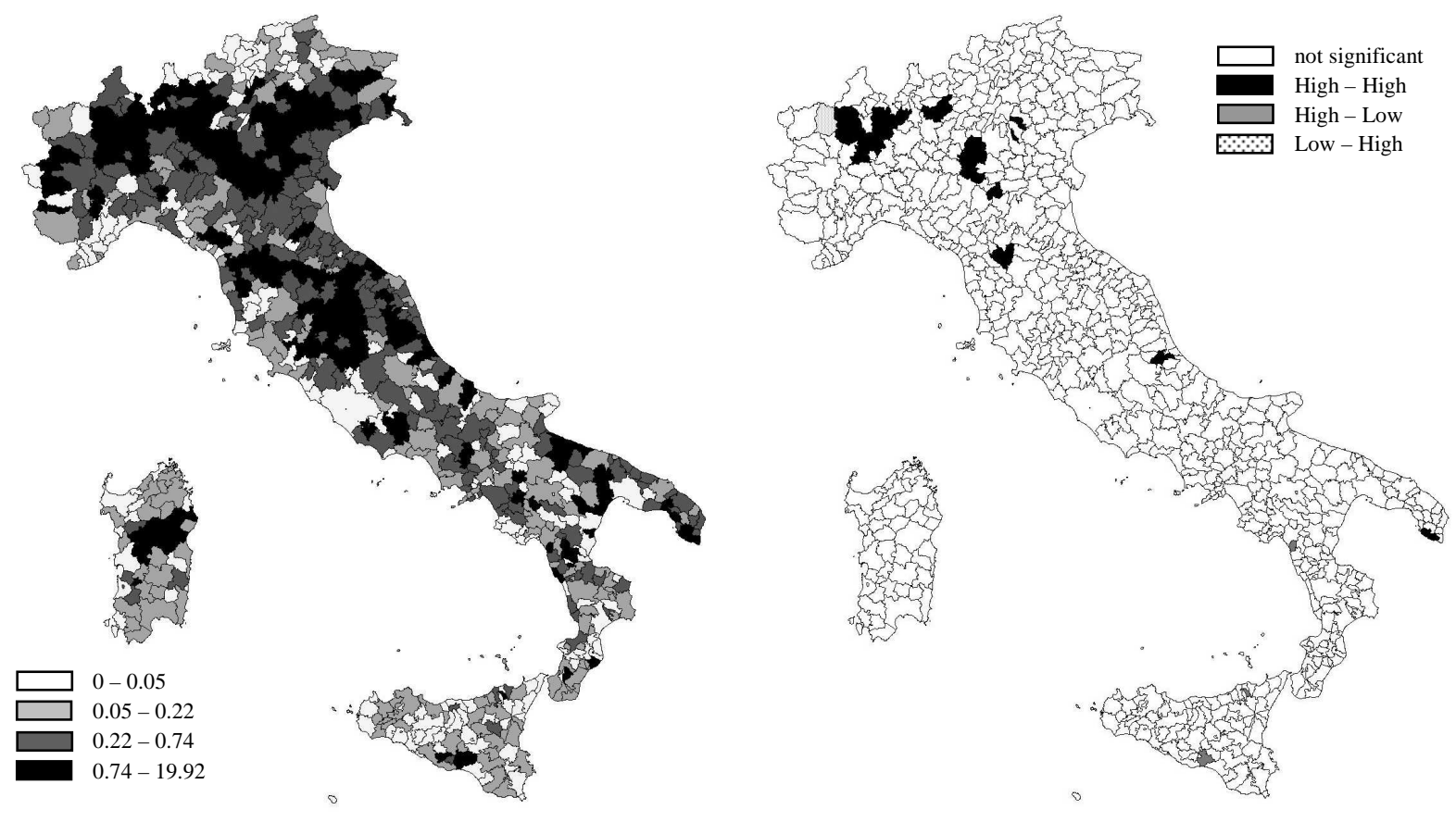

Figure 1. Manufacture of Textile. Spatial distribution of the location quotient (left, in quartile) and local Moran's I significance map (right).


Figure 2. Tanning and dressing of leather. Spatial distribution of the location quotient (left, in quartile) and local Moran's I significance map (right). 

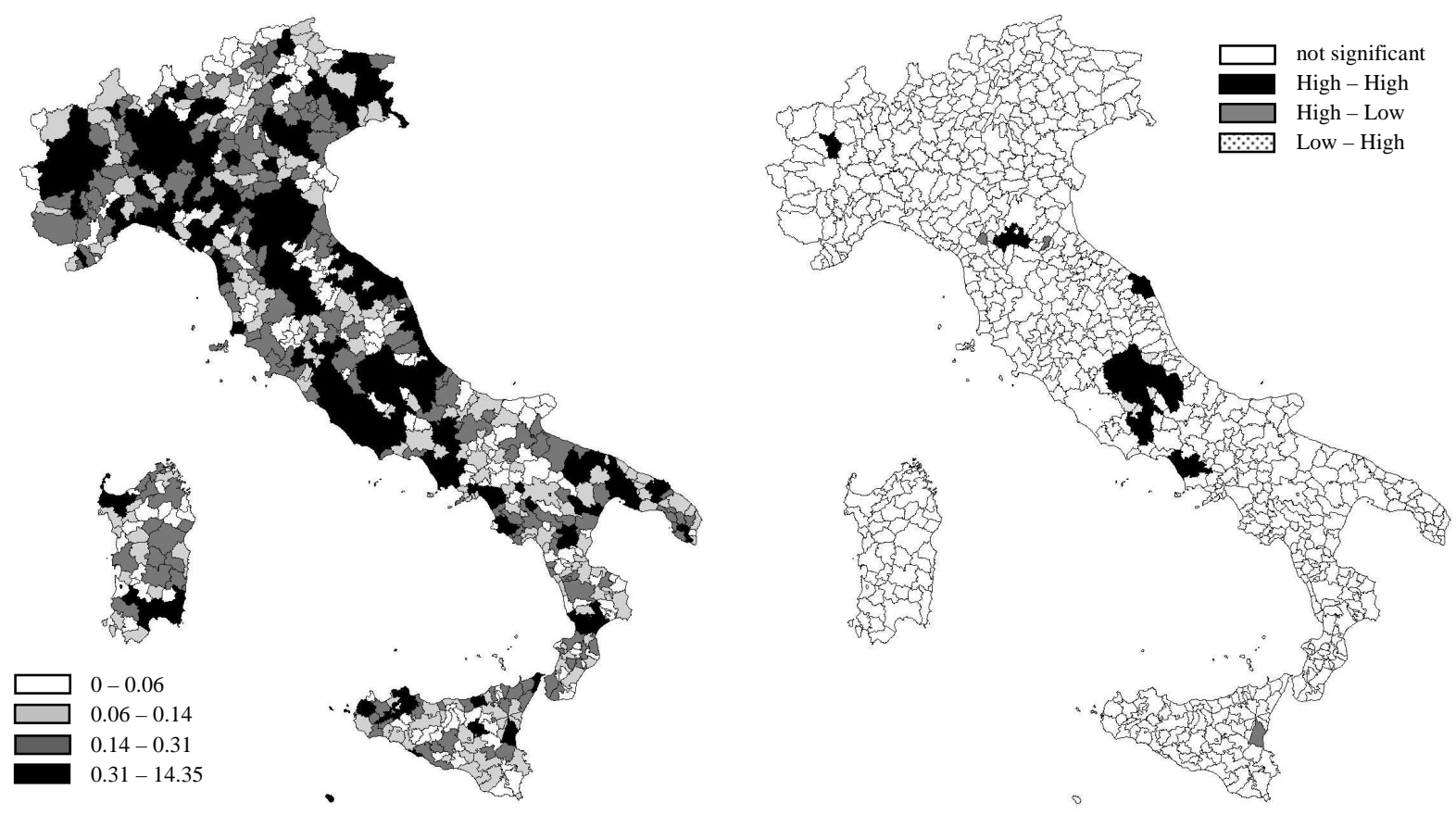

Figure 3. Manufacture of radio, television and communication equipment. Spatial distribution of the location quotient (left, in quartile) and local Moran's I significance map (right).
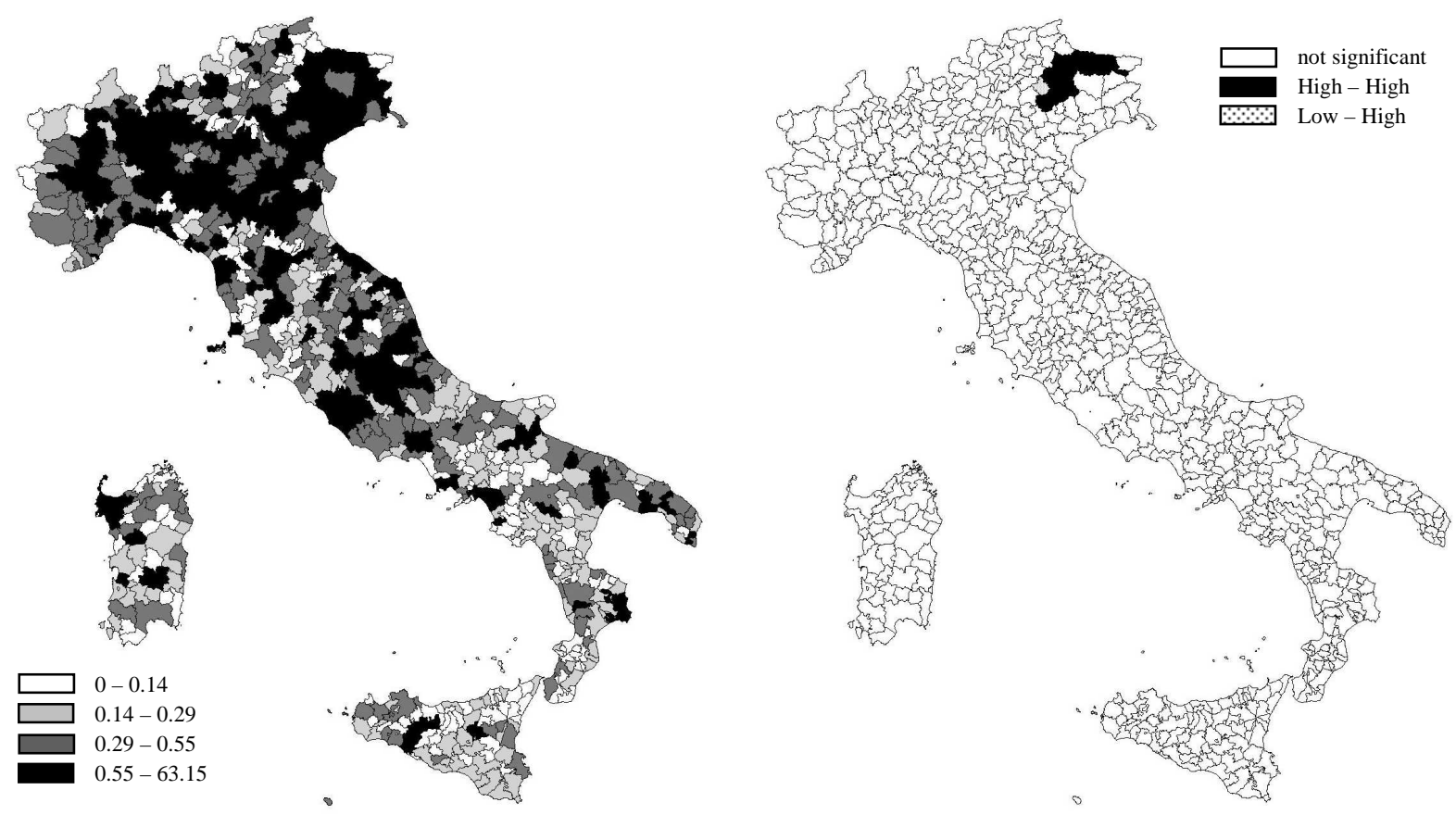

Figure 4. Manufacture of medical, precision and optical instruments. Spatial distribution of the location quotient (left, in quartile) and local Moran's I significance map (right). 

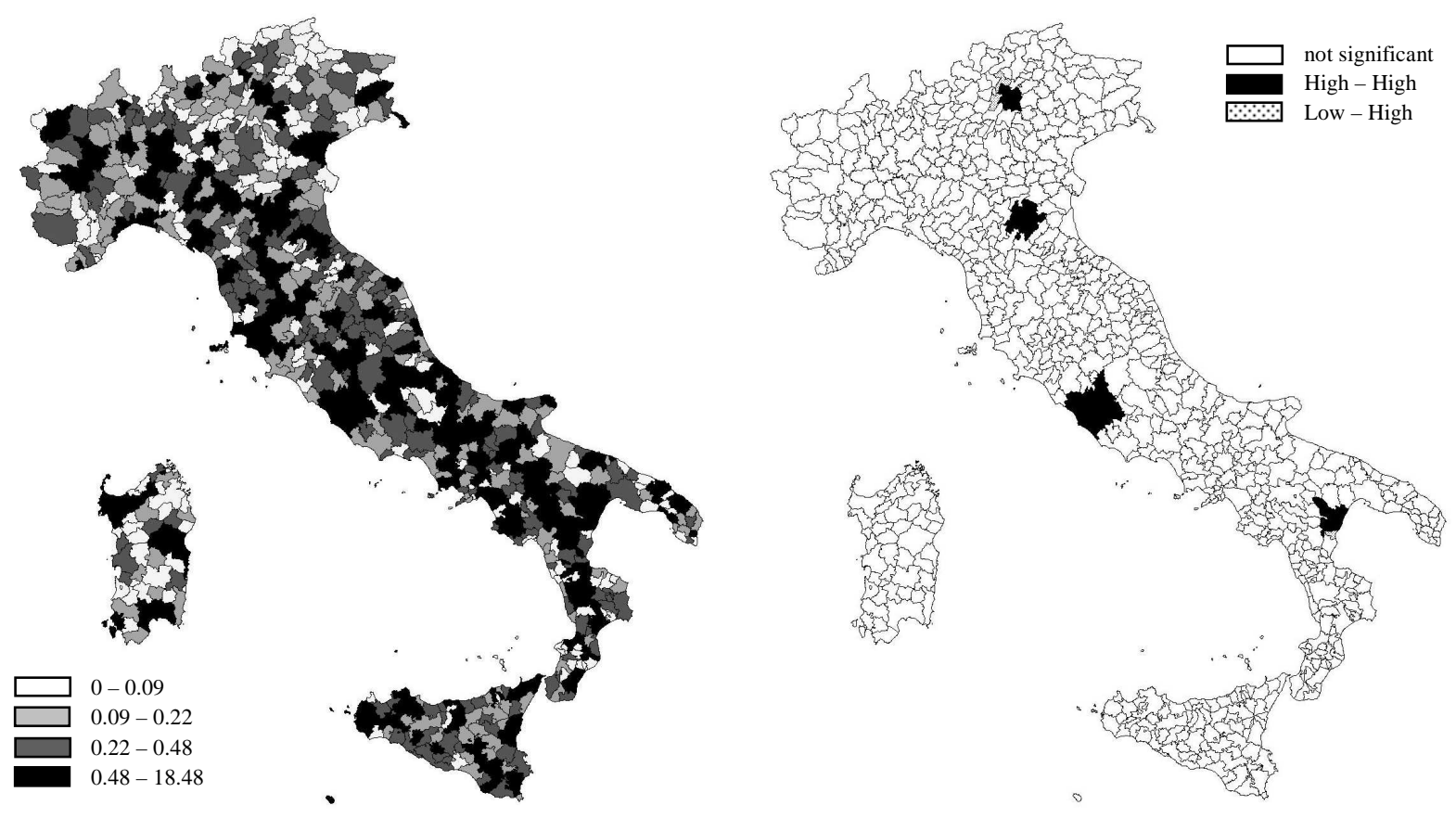

Figure 5. Research and Development. Spatial distribution of the location quotient (left) and local Moran's I significance map (right). 


\section{Appendix. List of 2-digit NACE industries in the sample}

\section{Manufacturing}

\begin{aligned} & \hline 2 -digit id \\ & \hline 15 Manufacture of food products and beverages \\ & 16 Manufacture of tobacco products \\ & 17 Manufacture of textiles \\ & 18 Manufacture of wearing apparel \\ & 19 Tanning and dressing of leather \\ & 20 Manufacture of wood and of products of wood \\ & 21 Manufacture of pulp, paper and paper products \\ & 22 Publishing, printing and reproduction of recorded media \\ & 23 Manufacture of coke, refined petroleum products \\ & 24 Manufacture of chemicals and chemical products \\ & 25 Manufacture of rubber and plastic products \\ & 26 Manufacture of other non-metallic mineral products \\ & 27 Manufacture of basic metals \\ & 28 Manufacture of fabricated metal products \\ & 29 Manufacture of machinery and equipment \\ & 30 Manufacture of office machinery and computers \\ & 31 Manufacture of electrical machinery \\ & 32 Manufacture of radio, television and communication \\ & 33 Manufacture of medical, precision and optical instruments \\ & 34 Manufacture of motor vehicles \\ & 35 Manufacture of other transport equipment \\ & 36 Manufacture of furniture \\ & 37 Recycling \\ & 45 Construction \\ & \hline\end{aligned}

\section{Services}

\begin{tabular}{cl}
\hline 2-digit id & \multicolumn{1}{c}{ sector } \\
\hline \hline 50 & Sale, maintenance and repair of motor vehicles \\
51 & Wholesale trade and commission trade \\
52 & Other wholesale \\
55 & Hotels and restaurants \\
60 & Land transport; transport via pipelines \\
61 & Water transport \\
62 & Air transport \\
63 & Supporting and auxiliary transport activities \\
64 & Post and telecommunications \\
65 & Financial intermediation, except insurance and pension \\
66 & Insurance and pension funding, except compulsory pension \\
67 & Activities auxiliary to financial intermediation \\
70 & Real estate activities \\
71 & Renting of machinery and equipment without operator \\
72 & Computer and related activities \\
73 & Research and development \\
74 & Other business activities \\
\hline
\end{tabular}

